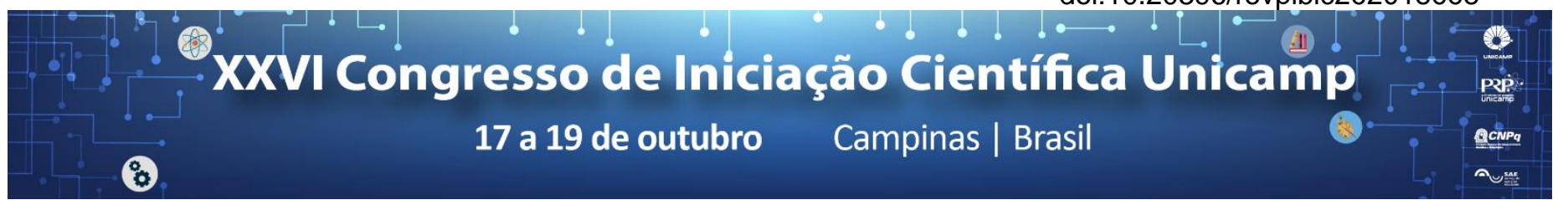

\title{
Análise geoquímica de água de escolas de Santarém, região Oeste do Pará, Amazônia e prováveis efeitos na saúde dos escolares.
}

\author{
Jessica T. Kondo*, Marina S. C. Meschede, Bernardino R. Figueiredo.
}

\begin{abstract}
Resumo
Na região oeste do Estado do Pará, o suprimento de água para consumo humano é muito favorecido pela ocorrência do aquífero Alter-do-Chão, descrito em estudos anteriores por Tancredi (1996) e Meschede (2018). O presente estudo faz parte de um projeto maior, e contém dados de parâmetros de qualidade e composição química da água subterrânea, utilizada para consumo humano, em duas escolas de ensino fundamental na cidade de Santarém (PA) e da composição mineralógica e química de amostras de rochas da Formação Alter-do-Chão, PA. Após as análises, contatou-se que a água é bicarbonatada sódica a cloretada sódica, e os valores de $\mathrm{pH}$ variam de 4,5 a 5,2. Além disso, observou-se teores de alumínio mais altos que os valores da Portaria 2914 além de elevadas concentrações de nitrato. Já as amostras de rochas compreendem em sua maioria arenito e argilito. Os minerais mais abundantes são quartzo, feldspato e caulinita. Tendo esses resultados em vista, o objetivo principal dessa pesquisa é conhecer melhor a relação entre as águas do Aquífero Alter-do-Chão com as rochas da Formação e fortalecer a discussão sobre os efeitos em saúde dos escolares nessa cidade com base na água de consumo.
\end{abstract}

\section{Palavras-chave:}

Hidrogeoquímica, saúde, Santarém.

\section{Introdução}

A qualidade de água de consumo humano foi examinada na cidade de Santarém em duas escolas de ensino fundamental, localizadas no Bairro Maracanã (poço profundo $>250 \mathrm{~m}$ do sistema de distribuição da empresa COSANPA) e no Bairro Nova República (poço raso <18m). A água é captada por poços subterrâneos que interceptam o aquífero Alter-do-Chão, PA. Foram obtidos dados de parâmetros de qualidade e composição química da água subterrânea além da composição mineralógica e química de rochas da Formação Alter do Chão. As concentrações dos elementos químicos nas amostras de água foram comparadas com os valores de referência da Portaria 2914/2011 do Ministério da Saúde para água de consumo humano, de forma a identificar elementos em concentrações prejudiciais à saúde.

\section{Resultados e Discussão}

As amostras de água foram coletadas de bebedouros e torneiras de cozinha das duas escolas de ensino fundamental, no município de Santarém.

Após as análises de cromatografia iônica e de ICPMS, constatou que a água é bicarbonatada sódica e os valores de $\mathrm{pH}$ da água variaram de 4,5 a 5,2. Além disso, foram observadas elevadas concentrações de nitrato $(7,43$ $\mathrm{mg} / \mathrm{L}$ ) e teor de alumínio nas amostras de água, estando em desacordo com a Portaria 2914 do Ministério da Saúde.

Já para as rochas da Formação Alter do Chão, foram realizadas análises de difração e flourescência de raio $\mathrm{X}$, obtendo-se como resultados arenito eventualmente contendo cimento ferruginoso, argilito, horizontes conglomeráticos e concreções ferruginosas. Os minerais mais abundantes são quartzo, feldspato, caulinita podendo ocorrer ainda hematita. A composição química do arenito é variável com $87-97 \% \mathrm{SiO}_{2}, \quad 0,3-2,6 \% \mathrm{Al}_{2} \mathrm{O}_{3}$ e $0,12-8,1 \%$ $\mathrm{Fe}_{2} \mathrm{O}_{3}$ e teores baixos de metais como $\mathrm{Pb}, \mathrm{Cu}$ e $\mathrm{Zn}$.

\section{Conclusões}

Os efeitos na saúde, relacionados ao consumo de água ácida, incluem alterações gástricas e intestinais, e o risco de contaminação por metais ao longo do transporte da água até o ponto de consumo. Com relação ao nitrato, a ingestão deste pode provocar vários efeitos prejudiciais à saúde, como o risco aumentado de certos tipos de câncer, metahemoglobina infantil, cancros do trato digestivo, entre outros.

Em relação ao alumínio, alguns estudos têm demonstrado uma relação entre exposição crônica ao alumínio e a doença de Alzheimer. Analisando-se os resultados das amostras de rochas e água, conclui-se que grande parte da contribuição dos metais perigosos em água derivam dos processos de interação água-rocha, em que a alta concentração de alumínio poderia ser explicada pela desestabilização dos feldspatos. A contaminação da água por nitrato pode estar indicando deficiência de saneamento gerando contaminação da parte superior do aquífero captado por poços rasos em Santarém.

\section{Agradecimentos}

Gostaria de agradecer à Profa. Dra. Marina Meschede da UFOPA por sua orientação durante o projeto e o trabalho de campo realizado em julho de 2017, ao Prof. Dr. Anderson Mendes da UFPA pelo auxílio concedido durante 0 trabalho de campo, aos funcionários do laboratório do IG-Unicamp pelos serviços prestados e ao $\mathrm{CNPq}$ e SAE-Unicamp por financiar o presente projeto 305119/2015-85.

MESCHEDE, M.S.C. Implicações para a saúde dos escolares a partir do consumo de água e material particular atmosférico inalado em escolas de Santarém e Mojuí dos Campos, Pará, Amazônia. 2018. Tese (Doutorado em Saúde Pública) Universidade Federal do Oeste do Pará, Santarém.

TANCREDI, A.C.F.N.S. Recursos hídricos subterrâneos de Santarém: Fundamentos para uso e proteção. 1996. Tese (Doutorado em Geologia) Universidade Federal do Pará, Belém. 